This article originally appeared in College and Undergraduate Libraries 15, no. 4, 2008, 432-437

http://dx.doi.org/10.1080/10691310802554895

\title{
Using Wikipedia to Teach Information Literacy
}

Eric Jennings

ABSTRACT. Today's college student often starts his/her research by using a search engine. Because of this, Wikipedia is increasingly becoming the go-to reference resource for the newest generation of students. However, many students do not know about the problems (e.g., vandalism) associated with this tool other than ambiguous warnings from librarians and faculty who say that it should not be used for research. Librarians and faculty should help remove the stigma associated with Wikipedia by embracing this website and its imperfections as a way to make information literacy instruction valuable for the $21^{\text {st }}$ century student.

KEYWORDS. Wikipedia, information literacy, instruction, students, Internet, college and university libraries

Eric Jennings (M.A. Library and Information Science, University of lowa) is Reference and Instruction Librarian, University of Wisconsin - Eau Claire, Eau Claire, WI 54702 (address email to:

jenninge@uwec.edu). 
Wikipedia, the free online encyclopedia that some librarians love and others love to hate, is increasingly becoming the go-to reference resource for a new generation of students. It is easy to use, and the ability to access information from one's desktop, laptop, or cell phone makes it quicker than going through the reference collection. However, there are problems with Wikipedia: many students believe that it is a one-stop-shop for all their information needs, vandals deliberately change entries, etc. These problems have led some librarians and faculty to tell students not to use this resource (Jaschik 2007). This, however, flies in the face of two key components of information literacy: students learning to find and evaluate resources; it implies that students cannot make good decisions about the information they seek or find. Instead of objecting to its use, librarians and faculty should embrace Wikipedia and its imperfections as an instrument that can help make information literacy instruction relevant and effective.

\section{WHY IS WIKIPEDIA RELEVANT TO LIBRARIANS?}

As the newest generation of students comes to college having grown up with computers and the Internet, many expect or assume that using online resources like Wikipedia is valid. According to an Online Computer Library Center (OCLC) report on college students' perceptions of libraries and information resources, $89 \%$ of students start research using a search engine (68\% use Google) while only 2\% use library websites first (De Rosa et al. 2006). Moreover, because Google often ranks Wikipedia articles in the top ten, students inevitably use Wikipedia. A recent Pew Internet \& American Life Project survey found that $44 \%$ of online adult Internet users aged $18-29$ and $50 \%$ of adults with a college degree use Wikipedia (Rainie and Tancer 2007). Because students are already using Wikipedia, librarians need to be familiar with this resource and should try to leverage it to teach information literacy skills. 
In order to understand how to use Wikipedia as an information literacy tool, librarians should know how Wikipedia formats, collects, and disseminates information. Depending on the breadth and depth of an article, some of the elements mentioned below may or may not be present.

- Discussion: Wikipedia contributors use this page to hash out contentious issues rather than continuously edit an article.

- Edit This Page: Where edits to an article are made.

- History: All edits are logged on this page. One's IP address or user name (if a registered user), the date, and time of an edit are logged. Users can also compare different versions of an article here.

- Hyperlinks: Blue hyperlinks are active links to another Wikipedia entry. Red hyperlinks are those that someone has tagged as a candidate for entry into Wikipedia.

- Contents: Provides an outline of the article.

- Categories: These hyperlinks are similar to the Library of Congress Subject Headings.

- See Also: Hyperlinks to other Wikipedia articles that may be of interest.

- Notes (a.k.a. References, Footnotes, etc.): Direct references to sources used to write an article.

- Sources: A reference list (bibliography).

- Further Reading: Books, articles, etc. that may be of interest.

- External Links: Links to websites outside of Wikipedia.

- Template: Found at the bottom, templates are another way to categorize an article within a larger subject area. E.g., Marshall Plan is part of the Cold War template.

\section{USING WIKIPEDIA TO TEACH INFORMATION LITERACY}

For nearly ten years, the ACRL Information Literacy Competency Standards for Higher Education (American Library Association 2000) have given librarians and faculty an authoritative source to use in 
the classroom with students when teaching about information literacy. By utilizing Wikipedia, a resource that many students have heard is off-limits in conjunction with the ACRL Standards, librarians can engage students in learning information literacy skills.

Teaching information literacy does not have to be as prescriptive as outlined below. It has been laid out in this format so that one can choose to teach specific Standards rather than all Information Literacy Standards at once. Although these examples are very student research oriented, many of the concepts work just as well outside of academia since students are not the exclusive users of Wikipedia.

Standard One: The information literate student determines the nature and extent of the information needed.

Wikipedia, like most encyclopedias, can be used to help a student understand an idea or topic by giving him/her the background knowledge of said topic. By using an example article in a print encyclopedia and comparing that with an article in Wikipedia, librarians can show students how articles in both resources are summarizations and not actual research.

Standard Two: The information literate student accesses needed information effectively and efficiently.

Encyclopedias like Wikipedia are good places to start but they do not always have enough information required for student research. However, encyclopedias provide avenues to further one's research. In Wikipedia, these avenues are an articles' notes, sources, external links, etc. It is imperative that librarians and faculty tell students that there is nothing inherently wrong with using an encyclopedia as a way to find more resources; they are an efficient and effective way to start research on one's topic.

Another way to use Wikipedia to teach Standard Two is to discuss keywords and how Wikipedia can help students brainstorm them. Within Wikipedia, many of the keywords are hyperlinks. Explain that when one is having a difficult time finding information in a database or the online catalog, using 
different keywords can help speed up the process and produce better results. Telling students that librarians run multiple searches using different keywords can help alleviate the fear and frustration of research.

Standard Three: The information literate student evaluates information and its sources critically and incorporates selected information into his or her knowledge base and value system.

Because there are flaws with Wikipedia, asking students about the pros and cons of using an encyclopedia that can be edited by anyone should elicit discussion on authority, accuracy, and other evaluation criteria. If making a pro/con list does not generate the level of discussion needed to understand this Standard, deliberately changing an article to say something students know is false and/or letting students edit a Wikipedia page is a quick, simple way to make the point of Wikipedia's lack of fixity and that not everyone is an expert on Wikipedia. When demonstrating this, please note that there is an option to preview any changes. This is the recommended course of action when "vandalizing" an article since it shows exactly what the page would look like if it were saved. Finally, using Stephen Colbert's "Wikiality" (Colbert 2006), in which Colbert encourages people to vandalize Wikipedia, is a humorous way to get students to think about potential problems with Wikipedia and why it needs to be evaluated critically.

Purposely vandalizing Wikipedia or using Colbert's video may seem like over-the-top ways to teach about critically evaluating resources. Nevertheless, it gives librarians the opportunity to open a discussion with students about evaluating all information sources critically.

Standard Four: The information literate student, individually or as a member of a group, uses information effectively to accomplish a specific purpose.

Using Wikipedia as a starting point is one way to use it to accomplish a specific purpose, but others may not be so evident. If students are having a hard time putting their ideas together clearly, showing a Wikipedia article and how it is structured (see: Contents) with an introductory paragraph and 
separated by sections that flow together to the conclusion is useful. Some professors are also using Wikipedia as a way for students to submit papers for an assignment (Wikipedia Contributors 2008). Students can either write a new article that needs to be added to the encyclopedia or update a previously written article. Not only does this provide an outlet for students to publish their work, but it also engages them in new media. Many people, not just Wikipedians (the term used to describe those who edit Wikipedia), are using wikis as a collaborative tool at work, among friends, or in working with colleagues around the world. Showing students how wikis work can help prepare them for life after graduation where they will find that different media suit different needs.

Standard Five: The information literate student understands many of the economic, legal, and social issues surrounding the use of information and accesses and uses information ethically and legally.

Finally, citing one's source is just as important in Wikipedia as it is in a research paper or presentation. Within Wikipedia, one often sees "Citation Needed" where a footnote reference should be. This indicates that the claim made in that sentence or paragraph needs to be verified. If Wikipedians are as concerned with verifying resources as professors are, students may take notice of its importance. From this, a librarian can discuss plagiarism, paraphrasing, and citation styles with students. Providing examples in popular culture of people who have been called to task for not properly citing their materials (e.g., Doris Kearns Goodwin and Stephen Ambrose are two examples that students might know) is an additional way to engage students in understanding why using information properly is important. If a librarian wants to go into greater depth on Standard Five, presenting students with information on copyright and fair use would further their understanding of this Standard.

\section{CONCLUSION}

In conclusion, librarians should be educating students on the proper use of all information sources, including Wikipedia. Discriminating against Wikipedia just because it is Wikipedia sends the wrong message. Becoming information literate is more than just knowing how to write a research paper 
or find information in an online catalog or in a database. Students are exposed to information almost every minute that they are awake. They get text messages and email; read books, blogs, and news on the web; watch videos on YouTube; go to class and hear a professor's lecture; and talk to their friends. If librarians and faculty want to help students be successful in the information age, they need to help students become information literate. By interacting with and utilizing Wikipedia as a teaching instrument, librarians can help remove the stigma from this resource and instill in students the tools and abilities necessary to be critical thinkers and lifelong learners in using all information sources. 


\section{REFERENCES}

American Library Association. 2000. Association of College and Research Libraries. http://www.ala.org/ ala/acrl/acrlstandards/standards.pdf.

Colbert, S. 2006. Wikiality. Comedy Central. http://www.comedycentral.com/colbertreport/ videos.jhtml?videold=72347.

De Rosa, C., J. Cantrell, J. Hawk, and A. Wilson. 2006. College students' perceptions of libraries and information resources. Dublin, OH: OCLC Online Computer Library Center. http://www.oclc.org/ reports/pdfs/studentperceptions.pdf.

Jaschik, S. 2007. A stand against Wikipedia. Inside Higher Ed. http://www.insidehighered.com/news/ 2007/01/26/wiki.

Rainie, L., B. Tancer. 2007. Wikipedia users. Pew Internet \& American Life Project. http://www.pewinternet.org/pdfs/PIP_Wikipedia07.pdf.

Wikipedia contributors. Wikipedia: School and university projects. 2008. Wikipedia. http://en.wikipedia.org/wiki/Wikipedia:School_and_university_projects. 